\title{
INDICADORES HEMATOLÓGICOS E BIOQUÍMICOS DO ESTRESSE EM TILÁPIAS (Oreochromis niloticus), SUPLEMENTADAS COM RACTOPAMINA
}

(Indicators hematological and biochemical stress in tilapia (oreochromis niloticus) supplemented with ractopamine)

Ana Paula Pereira Mundim, Francisco Ernesto Moreno Bernal, Leonardo Gomes Carrazza, Thiago Dias Trombeta, Rodrigo Roubach, Jurij Wacyk ${ }^{1}$

${ }^{1}$ Correspondência: paula_mundim@hotmail.com

RESUMO: Objetivou-se com este trabalho avaliar o efeito da ingestão de ractopamina nas concentrações 0 ppm (controle), 10 ppm, 20 ppm e 40 ppm na ração, sobre os parâmetros fisiológicos e imunológicos, por meio da análise dos parâmetros hematológicos e da concentração sérica de cortisol e lactato, em 80 tilápias do Nilo (Oreochromis niloticus) da linhagem GIFT, com peso médio de 500 gramas, distribuídas aleatoriamente em 16 caixas d'água, com capacidade para 500 litros, com a densidade de 5 animais. Retirando-se ao dia 01 animal de cada caixa e cada 20 dias, 2 peixes por caixa, totalizando 8 peixes de cada tratamento. Coletaram-se amostras de sangue para dosagem de cortisol, lactato e parâmetros hematológicos (contagem de hemácias, leucócitos, proteínas totais - PPT, volume globular - VG, hemoglobina. O lactato apresentou uma diminuição significativa $(p<0,05)$ nos dois tempos de coleta com 10 ppm $(3,79 \mathrm{mmol} / \mathrm{L}$ aos 20 dias e 1,58 $\mathrm{mmol} / \mathrm{L}$ aos 40 dias) e quando comparado ao controle $(4,61 \mathrm{mmol} / \mathrm{L}$ ao dia $0,4,78$ $\mathrm{mmol} / \mathrm{L}$ aos 20 dias e 4,54 aos 40 dias) e a mesma concentração diferiu quando comparada com 40 ppm de ractopamina aos 40 dias $(3,15 \mathrm{mmol} / \mathrm{L})$. Os parâmetros avaliados, cortisol, contagem de hemácias, leucócitos, volume globular - VG, hemoglobina, não apresentaram diferença significativa $(p<0,05)$ entre tratamentos e tempos de coleta. Os resultados obtidos neste trabalho não demonstraram um estresse fisiológico produzido pela ingestão de ractopamina nas concentrações de 10, 20 e 40 ppm pelos animais. Entretanto, mais estudos acerca do tema devem ser realizados, para que o uso do aditivo seja recomendado de forma segura, quanto ao bem-estar dos peixes.

Palavras-chave: Piscicultura, Tilápia do Nilo, bem-estar animal, Beta-adrenérgico

ABSTRACT: The objective of this study was to evaluate the effect of ractopamine intake at concentrations of 0 ppm (control), 10 ppm, 20 ppm and 40 ppm in the diet on the physiological and immunological parameters, through the analysis of 
hematological parameters and serum concentration of cortisol and lactate in 80 Nile tilapia (Oreochromis niloticus) of the GIFT strain, weighing 500 grams, randomly distributed in 16 water tanks with a capacity of 500 liters, with the density of 5 animals. Withdrawing from day 0 to 1 animal in each box, and every 20 days, 2 fish per box, totaling eight fish each treatment. They were collected blood samples for cortisol assay, lactate and haematological parameters (red blood cell count, white blood cells, total protein - PPT, packed cell volume. - VG, hemoglobin, lactate showed a significant decrease $(p<0.05)$ at both times collection with $10 \mathrm{ppm}(3.79$ $\mathrm{mmol} / \mathrm{L}$ to 20 days and $1.58 \mathrm{mmol} / \mathrm{L}$ at 40 days) and compared with the control (4.61 $\mathrm{mmol} / \mathrm{L}$ at day $0,4.78 \mathrm{mmol} / \mathrm{L}$ to 204.54 days and 40 days) and the same concentration differed compared with $40 \mathrm{ppm}$ of ractopamine at 40 days $(3.15 \mathrm{mmol}$ / L) The parameters evaluated, cortisol, blood counts, white blood cells, packed cell volume. - VG, hemoglobin, showed no significant difference $(p<0.05)$ between treatments and collection times. The results of this study did not demonstrate a physiological stress produced by ractopamine intake in concentrations of 10, 20 and $40 \mathrm{ppm}$ for animals. However, more studies on the subject should be carried out so that the additive use is recommended securely on the welfare of fish.

Key Words: Pisciculture, Nile tilapia, animal welfare, Beta-adrenergic 


\section{INTRODUÇÃO}

$\mathrm{Na}$ última década a aquicultura passou por um intenso processo de desenvolvimento. No Brasil, a atividade Cresceu $56 \%$ nos últimos 12 anos e tem se firmado cada vez mais em decorrência dos recursos hídricos disponíveis, clima favorável, mão de obra relativamente barata e crescente mercado interno, além de possuir cerca de 5,5 milhões de hectares de água, aproximadamente 208 reservatórios potenciais para a atividade e uma costa marítima de 8.000 (Barcellos et al., 1999). Nesta década (MPA, 2010), o país chegou ao sexto lugar como produtor de tilápia cultivada no mundo, e a Tilápia do Nilo (Oreochromis niloticus) representou aproximadamente $47 \%$ da produção total de pescados em aquicultura de água doce.

A trilápia do Nilo (Oreochromis niloticus) é uma espécie de peixe precoce, que apresenta excelente desempenho em diferentes regimes de criação. Sua produção tem crescido acentuadamente, sendo hoje uma das espécies mais indicadas para o cultivo intensivo, devido às qualidades para a produção, bem como a excelente textura da carne (Furuya et al., 2010).

$O$ mercado de peixes vem se tornando cada vez mais exigente e crescente, 0 peso médio de abate comercial de tilápias vem aumentando, o que consequentemente ocasiona em um maior teor de gordura depositada na carcaça, a qual é indesejada por esse novo mercado consumidor, que é mais informado e busca uma alimentação mais saudável. A procura por carnes magras e com pouca gordura aumentou nos últimos anos, fazendo com que novas opções sejam estudadas e avaliadas durante a produção de animais. Dentre elas os aditivos alimentares, principalmente os modificadores de carcaça que se destacam por conferir melhorias ao produto final.
Apesar de inúmeras pesquisas na área de aquicultura, o conhecimento relacionado à nutrição de peixes ainda é escasso, quando comparado a outras espécies de importância zootécnica, onde a tecnologia é amplamente empregada nos estágios de formulação e manipulação de rações nutricionalmente eficientes (Pezzato et al., 2004). Um exemplo de tecnologia amplamente utilizado na produção de algumas espécies animais é o emprego de aditivos na ração (entre eles, antioxidantes, flavorizantes, modificadores metabólicos, promotores de crescimento, entre outros).

Entre esses, está a ractopamina, um repartidor de energia, agonista $\beta$ adrenérgico $(A \beta A)$, caracterizado como uma catecolamina sintética, conhecida por melhorar a eficiência alimentar, reduzir o conteúdo de gordura corporal e incrementar o crescimento muscular em animais (Wendelaar Bonga, 1997). Uma substância exógena que altera a maneira como os nutrientes são particionados para depósito muscular ou de gordura (Mills; Spurlock; Smith, 2003).

A utilização do $\beta$-agonista ractopamina como promotor de crescimento em dietas para animais melhora o desempenho da produção e as características da carcaça de diversas espécies domésticas. Esses agonistas por meio da aceleração e modificação de vias metabólicas específicas, principalmente as relacionadas com o metabolismo das proteínas e dos lipídeos.

Em granjas de suínos a utilização do cloridrato de ractopamina na dieta, tornou-se indispensável para praticamente toda produção comercial nacional, exceto em animais destinados a exportação para países específicos como os da União Europeia.

Já para animais aquáticos, como os peixes, existem poucos estudos sobre os efeitos e níveis adequados de 
ractopamina na dieta. Em geral a ractopamina é adicionada à ração e fornecida aos animais na fase de terminação, idade a qual já tenham atingido a maturidade, ou seja, quando a capacidade de retenção das proteínas começa a ser menor. Neste momento associa-se que os efeitos dos betaadrenérgicos sejam mais evidentes.

Segundo Marchant-Forde et al. (2003), a suplementação com ractopamina pode ter efeito negativo sobre o bem-estar animal, gerando alterações fisiológicas típicas de estresse, que podem refletir na qualidade do produto final.

$O$ estresse em piscicultura intensiva pode ser proveniente de várias fontes, das quais são práticas comumente utilizadas, como por exemplo, a manipulação dos animais, o emprego de alta densidade de estocagem, o transporte, interações biológicas, qualidade da água, manejo de alimentação, incluindo a utilização de aditivos nutricionais. a suplementação com ractopamina pode ter efeito negativo sobre 0 bem-estar animal, gerando alterações fisiológicas típicas de estresse, que podem refletir na qualidade do produto final.

A maioria dos trabalhos realizados com ractopamina restringe-se a avaliações de desempenho, características de carcaça e qualidade de carne. No entanto, existem poucas informações na literatura demonstrando os efeitos deste aditivo sobre a susceptibilidade ao estresse dos animais, sobretudo em peixes, nos quais este aditivo não é usualmente utilizado, fazendo-se necessário um maior conhecimento para sua utilização segura. Portanto, o presente trabalho objetivou-se avaliar o efeito da ingestão de ractopamina na ração, sobre os parâmetros fisiológicos e imunológicos em tilápias do Nilo da linhagem GIFT, avaliando os parâmetros hematológicos e a concentração sanguínea de cortisol e lactato.

\section{MATERIAL E MÉTODOS}

O experimento foi realizado no Núcleo de Tecnologia em Piscicultura e Pecuária da Secretaria de Estado da Agricultura, Abastecimento e Desenvolvimento Rural do Distrito Federal, localizado em Brasília-DF. As análises bioquímicas e hematológicas foram realizadas no Laboratório de Patologia Clínica Veterinária e Laboratório de Bem-estar Animal da Universidade de Brasília.

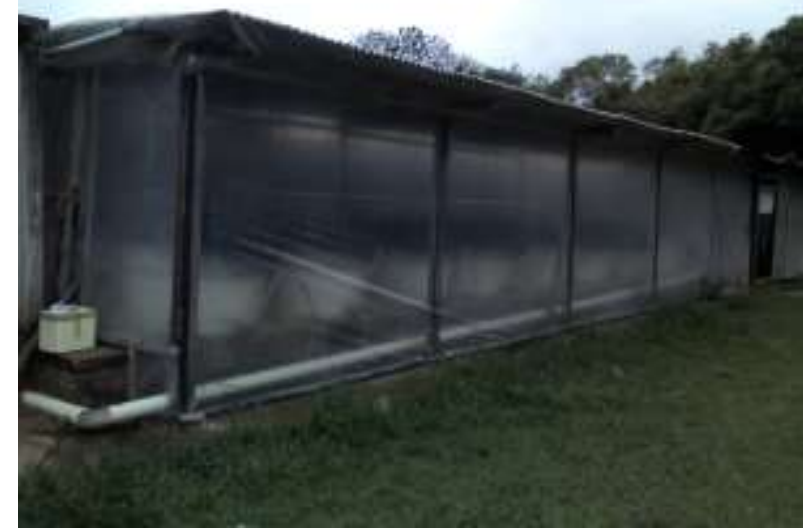

Figura 2. Local do experimento Núcleo de Tecnologia em Piscicultura e Pecuária da Secretaria de Estado da Agricultura, Abastecimento e Desenvolvimento Rural do Distrito Federal, localizado em Brasília-DF.

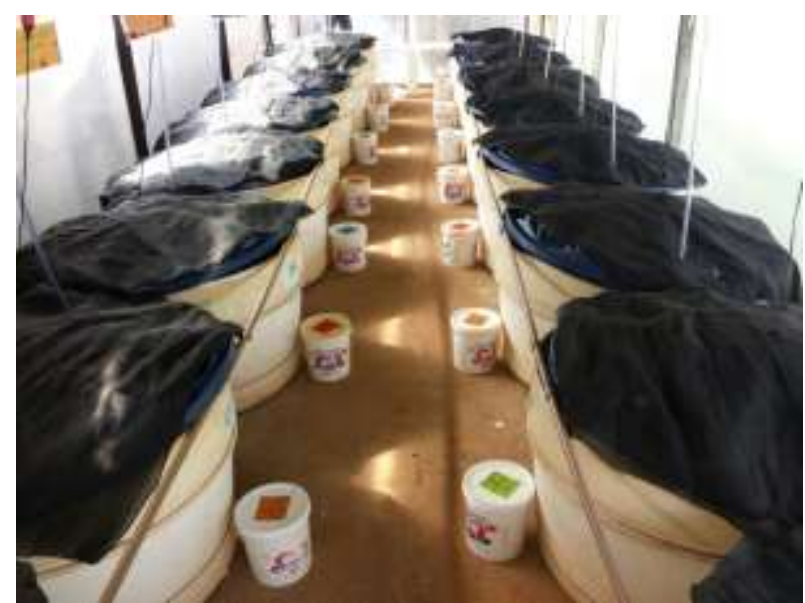

Figura 3. Local do experimento Núcleo de Tecnologia em Piscicultura e Pecuária da Secretaria de Estado da Agricultura, Abastecimento e Desenvolvimento Rural do Distrito Federal, localizado em Brasília-DF. 
Foram utilizados 80 peixes, tilápias do Nilo (Oreochromis niloticus) da linhagem GIFT, machos revertidos, com peso médio de 500 gramas, distribuídos aleatoriamente em 16 caixas d'água de amianto, com capacidade de 500 litros, totalizando 5 animais por caixa durante 40 dias. Os animais foram identificados individualmente utilizando-se microchips. A temperatura do sistema foi mantida à $27^{\circ} \mathrm{C}$ por termostatos individuais em cada caixa.

As rações recebidas pelos peixes foram preparadas na Universidade Federal de Viçosa, extrusadas e com diâmetro de $5 \mathrm{~mm}$, utilizando a formulação que cumpre com os exigências nutricionais para a espécie, segundo Boscolo (2009), como mostra a tabela 1.

Tabela 1- Níveis de garantia das rações utilizadas para alimentação dos machos revertidos de de tilápia do Nilo durante 0 período experimental.

\begin{tabular}{|c|c|}
\hline $\begin{array}{l}\text { Nutrientes }(\%) \\
\text { Nutrients }\end{array}$ & $\begin{array}{c}\text { Fase de } \\
\text { crescimento } \\
\text { Growing } \\
\text { phase }\end{array}$ \\
\hline $\begin{array}{l}\text { Energia digestivel ( } \mathrm{kcal} / \mathrm{kg}) \\
\text { Digestible energy }\end{array}$ & 3000,00 \\
\hline $\begin{array}{l}\text { Proteina bruta (minimo) } \\
\text { Crude protein (minimum) }\end{array}$ & 28,00 \\
\hline Gordura (minimo) & 4,00 \\
\hline $\begin{array}{l}\text { Fat (minimum) } \\
\text { Fibra bruta } \\
\text { (minimo-máximo) }\end{array}$ & 12,00 \\
\hline $\begin{array}{l}\text { Crude fiber (minimum- maximum) } \\
\text { Cálcio (minimo) } \\
\text { Calcium (minimum) }\end{array}$ & 1,20 \\
\hline $\begin{array}{l}\text { Fósforo (máximo) } \\
\text { Phosphorus (maximum) }\end{array}$ & 0,90 \\
\hline
\end{tabular}

Antes do período experimental, os peixes foram submetidos a um período de aclimatação de 15 dias. Nesse período os animais foram alocados em 2 tanques de alvenaria revestidos com azulejos com capacidade de 15.000 litros cada e receberam a mesma ração destinada ao grupo controle do experimento, ou seja, sem adição de ractopamina, porém com a mesma formulação básica. Durante o período experimental os peixes foram alimentados diariamente com as rações (duas vezes por dia) ad-libitum, sendo uma vez pela manhã e uma a tarde.

A densidade de peixes mantevese constante em torno de $10 \mathrm{~kg} / \mathrm{m}^{3}$, havendo um controle do volume de água de cada caixa após as eutanásias. Foram realizados monitoramentos diários, individuais em cada caixa, dos parâmetros físico-químicos da água, como temperatura, $\mathrm{pH}$, oxigênio dissolvido, amônia, nitrito e nitrato por meio de kit digital portátil.

Utilizou-se o sistema de cultivo de recirculação fechada, composto por um sistema de filtro mecânico e biológico, havendo um retorno da água para os tanques de $100 \%$ a cada 2 horas e uma renovação de no máximo $10 \%$ de água por dia.

O delineamento experimental foi inteiramente casualizado, composto por 4 tratamentos com ractopamina incorporada na ração em diferentes concentrações (0 ppm de ractopaminha, 10 ppm de ractopamina, 20 ppm de ractopamina e $40 \mathrm{ppm}$ de ractopamina). Os animais foram distribuídos em 16 caixas, totalizando 4 caixas por tratamento (4 repetições).

Foram realizadas coletas em 3 tempos distintos, sendo: $\mathrm{T}_{1}-0$ dias de tratamento e $\mathrm{T}_{2}-20$ dias de tratamento e $\mathrm{T}_{3}-40$ dias de tratamento. A cada tempo de coleta, 2 peixes de cada caixa foram escolhidos aleatoriamente para a coleta e anestesiados com eugenol na dosagem de $2,35 \mathrm{mg} / \mathrm{L}$. Foram coletados aproximadamente $3 \mathrm{~mL}$ de sangue de cada animal, por meio de punção da veia caudal, utilizando-se seringas descartáveis de $5 \mathrm{~mL}$ com agulhas $25 \times 7$, sendo estes animais posteriormente submetidos a eutanásia por secção da artéria branquial. Do volume total de sangue retirado de cada animal, $1 \mathrm{~mL}$ foi acondicionado e 
homogeneizado em tubos plásticos previamente identificados, contendo EDTA $(0,1 \mathrm{~mL})$ como anticoagulante para a preservação das amostras destinadas à ensaios hematológicos (Tavares-Dias et al., 2001), $1 \mathrm{~mL}$ de sangue foi armazenado em tubos plásticos sem anticoagulante para a obtenção de soro para a dosagem de cortisol e $1 \mathrm{~mL}$ em tubos contendo anticoagulante EDTA $(0,1 \mathrm{~mL})$ e fluoreto de sódio $(0,1 \mathrm{~mL})$ para a determinação da concentração plasmática de lactato.

Após a obtenção, as amostras foram encaminhadas ao Laboratório de Patologia Clínica Veterinária da Universidade de Brasília, para o armazenamento e processamento das análises.

Além das dosagens bioquímicas de cortisol e lactato, foram avaliados parâmetros hematológicos (contagem de eritrócitos, leucócitos, proteínas totais, volume globular, hemoglobina, hematócrito).

O hematócrito (em \%) foi determinado por meio da técnica de micro hematócrito com capilares heparinizados, segundo a técnica de Goldenfarb et al. (1971). A concentração de hemoglobina total $([\mathrm{Hb}]=\mathrm{g} / \mathrm{dL})$ foi determinada a partir da técnica do cianeto hemoglobina, proposta por Collier (1944). Para a contagem de eritrócitos e leucócitos foi empregada a solução de formol citrato, em que a contagem dos leucócitos totais e eritrócitos foi realizada de forma direta em câmara de Neubauer.

Para a determinação plasmática da concentração de lactato, as amostras foram centrifugadas para retirada do plasma, e posteriormente utilizando um kit comercial. Para a determinação da concentração de cortisol, foram utilizadas as frações de soro obtidas por centrifugação das amostras sem o uso de anticoagulante, utilizando-se 0 kit comercial.
A análise dos dados foi realizada utilizando-se o Programa Statistical Analysis System (SAS® v.9.3 Cary, North Carolina), sendo os resultados hematológicos e bioquímicos submetidos à análise de variância com posterior comparação de médias pelo teste de Tukey a $5 \%$ de significância. Para se determinar as correlações entre os resultados hematológicos e bioquímicos, foi aplicada a Correlação de Pearson. Em todas as análises realizadas, valores de $\mathrm{P}<0,05$ indicaram significância estatística.

\section{RESULTADOS E DISCUSSÃO}

No presente estudo, não houve diferença estatística significativa nas concentrações de cortisol nos diferentes níveis de ractopamina, em nenhum dos tempos de coleta, de acordo com a tabela 2. Corroborando com MarchantForde et al. (2003), que trabalhando com outras espécies de animais, avaliaram a concentração de cortisol em suínos na fase de terminação em animais que receberam ração suplementada com ractopamina, e concluíram que não houve diferença deste parâmetro entre os tratamentos.

Os resultados obtidos neste experimento, mesmo que não significativos entre os tratamentos e tempos de coleta, indicam que as concentrações de cortisol apresentaram-se elevadas inclusive no tempo 0 e nos animais controle, indicando um possível estresse gerado talvez pelo manejo ou pela mudança de ambiente. Tais valores quando comparados aos valores de referência descritos por Wendelaar Bonga (1997), que determinam que concentrações basais de cortisol de peixes em repouso devem ser inferiores a $40 \mathrm{ng} / \mathrm{mL}$, o que coincide com valores encontrados por diversos autores (16,43 a 46,32 ng/mL) (Barcellos Et al., 1999; Sanches, 2013). Segundo Summers et al., (2005), quando estressados, os peixes podem 
apresentar um aumento de cerca de 4 vezes nos valores do cortisol.

Os resultados encontrados para concentração de lactato e cortisol estão descritos na Tabela 2.

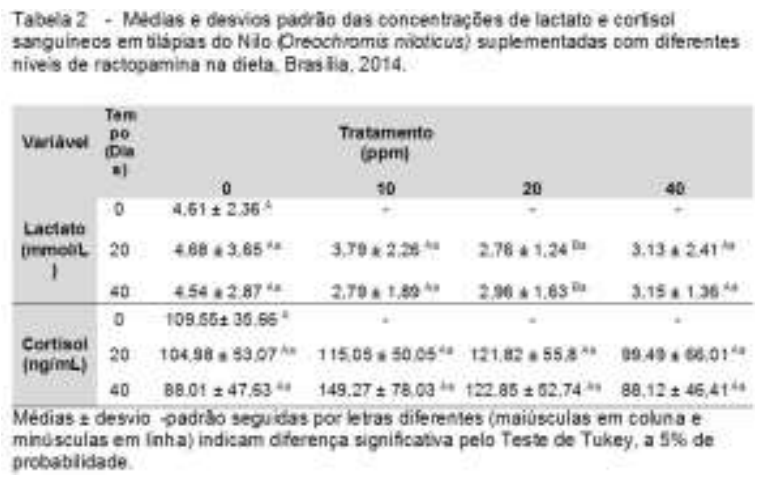

Os níveis de lactato apresentaram uma diminuição significativa no tempo de coleta (20 e 40 dias) no grupo suplementado com 20 ppm de ractopamina $(2,76 \pm 1,24$ e $2,96 \pm 1,63$, respectivamente), quando comparado ao controle e a tempo 0 (zero) (Tabela 2). Tais resultados diferem dos encontrados por Athayde, (2010), ao testar o estresse em suínos alimentados com ractopamina, onde não observaram efeito para esse parâmetro.

Em trabalho realizado por Brandão et al., (2006) o lactato apresentou uma diminuição significativa logo após o transporte quando comparado ao controle decorrentes da intensa natação do cardume no tanque de criação e as disputas territoriais que podem ter havido, sendo a tilápia um peixe de comportamento territorialista.

As concentrações de cortisol e de lactato não apresentaram correlação no estudo do coeficiente da correlação linear de Pearson com nenhuma outra variável analisada neste trabalho.

Os diferentes tratamentos avaliados não influenciaram $(P<0,05)$ a contagem total de hemácias, 0 percentual do hematócrito, o teor de hemoglobina, os valores de leucócitos, assim como demonstrado na Tabela 3. Estes resultados são semelhantes ao descrito por Barros et al. (2002) e Silva et al. (2012), ao avaliarem parâmetros hematológicos de alevinos de Tilápias do Nilo submetidos a situações de estresse, também não observaram alterações nestes parâmetros. $E$ também corroboram com Bicudo et al., 2012, ao analisar pacus criados em sistema de recirculação, alimentados com ração contendo ractopamina, onde não houveram diferenças significativas no hematócrito, Hemoglobina e hemácias entre os peixes alimentados com e sem o promotor de crescimento.

\begin{tabular}{|c|c|c|c|c|c|}
\hline \multirow[t]{2}{*}{ Vartandi } & \multirow{2}{*}{$\begin{array}{l}\text { Teen } \\
\text { po }\end{array}$} & \multicolumn{3}{|c|}{$\begin{array}{c}\text { Trataniemio } \\
\text { (topen) }\end{array}$} & \multirow[b]{2}{*}{40} \\
\hline & & D. & 10 & 20 & \\
\hline \multirow{3}{*}{$\begin{array}{l}\text { Hemogiedine } \\
\text { Govit) }\end{array}$} & 0 & $175=1902$ & $=$ & 7 & - \\
\hline & 20 & $7,48 \div 0,16=$ & $78+ \pm 0,79=$ & $2,37 \div 0,90=$ & $7.95=0.68=$ \\
\hline & $\infty$ & $7,06 \pm 0,71=$ & $6,7 \mathrm{~B}+1,57=$ & $5, \pi)=1,03=$ & $6.76=1,00=$ \\
\hline \multirow{3}{*}{ 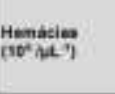 } & 0 & $2.50 \div 035^{\circ}$ & $=$ & . & + \\
\hline & 20 & $2,64+1,49=$ & $2,60+0,34=$ & $2,64 \pm 0,020$ & $2 n=0.45=$ \\
\hline & $\infty$ & $2.95: 0.57=$ & $2390 \times 0,3 t=$ & $2.78=0,58<$ & $2,81=0.41 \%$ \\
\hline \multirow{3}{*}{ HTO $\mathrm{CAl}$} & 0 & $33.22+3.7 \mathrm{a}^{2}$ & $=$ & + & - \\
\hline & 20 & $3004 \div 7.04=0$ & $31,05 \div 2.990$ & $36.28=5,70 *$ & $32,50 \div 7,36=$ \\
\hline & $\infty$ & $3138+50.86=$ & $32.2007 .7 \mathrm{ar}$ & $3705+8.23=$ & $38.75 \div 4.73 \mathrm{\omega}$ \\
\hline \multirow{3}{*}{$\begin{array}{l}\text { Leucoutiose } \\
\text { ave) }\end{array}$} & a & $48957 \neq 27100^{4}$ & 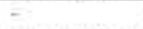 & - & - \\
\hline & 20 & $\cos 20=1453 t<$ & 64425 $\div 25041 \%$ & $42957+20030$ a & stroo $=35012=$ \\
\hline & $\infty$ & Was12 \pm 17444 h & $50000=11315=$ & $5+582+20157=$ & $60000+23800 \mathrm{oc}$ \\
\hline
\end{tabular}

Apesar de não terem apresentado diferenças significativos $(\mathrm{P}<0,05)$ entre os tratamentos e tempos, os valores de hemácias e o hematócrito apresentam-se ligeiramente elevados em relação aos valores de referência $(2,15 \pm 0,12$ e $27,85 \pm 1,65$, respectivamente) descritos por Ueda, (1997), diferindo de Brandão et al., 2006, que ao testarem a resposta ao estresse de Pirarucus submetidos a práticas de rotina em piscicultura.

De acordo com McDonald e Milligan, (1997), a diminuição de oxigênio no ambiente estimula a eritropoiese, aumentando o Hematócrito e as hemácias em peixes de água doce. Isso ocorre devido à liberação de catecolaminas, que causam mobilização das hemácias do baço aumentando sua quantidade no sangue e consequentemente, aumentando o HTO. O aumento de HTO também pode representar alterações eletrolíticas e 
influxo de água na célula (Mcdonald \& Milligan, 1997).

De acordo com Tavares \& Moraes (2004) o estresse leva ainda à ação dos glicocorticoides no organismo dos peixes, cujos níveis de cortisol no sangue são elevados e com isso ocorrem as modificações fisiometabólicas, observadas por meio do aumento do número de eritrócitos.

Possíveis hipóteses quando a não ocorrência de estresse, segundo Mills; Spurlock; Smith, (2003) a utilização contínua de Ractopamina torna o receptor inativo e desacopla o complexo receptor-Gs-adenilato ciclase. O efetor não acoplado migra para o espaço intracitoplasmático, levando à diminuição de receptores disponíveis na membrana. Essa redução na quantidade de receptores é denominada dessensibilização, causando a diminuição da resposta à estimulação betaadrenérgica da RAC. Da mesma forma, no espaço intracitoplasmático, o receptor betaadrenérgico pode ser consumido, conhecido como sequestro, - que acarreta a diminuição de receptores celulares. Esta variação no número de receptores por unidade de sarcolema é denominada "downregulation".

De acordo com a análise do coeficiente da correlação linear de Pearson não foram encontradas correlações significativas entre as médias das concentrações de hemácias, hemoglobina, leucócitos e proteínas totais com nenhuma das variáveis analisadas.

\section{CONCLUSÃO}

Os resultados obtidos pelos indicadores hematológicos e bioquímicos neste trabalho não apontaram para um estresse fisiológico produzido pela ingestão de ractopamina nas concentrações de 10, 20 e 40 ppm pelos animais, entretanto, mais estudos acerca do tema devem ser realizados, para que 0 uso do aditivo seja recomendado de forma segura, quanto ao bem-estar dos peixes.

\section{NOTAS INFORMATIVAS}

Este experimento foi submetido à avaliação pelo Comitê de Ética no Uso Animal do Instituto de Ciências Biológicas da Universidade de Brasília e aprovado sob protocolo - CEUA/UnB (70411/2014).

\section{REFERÊNCIAS}

ATHAYDE N. B. Desempenho,
qualidade de carne e estresse de
suínos suplementados com
ractopamina. Dissertação de mestrado,
Universidade Estadual Paulista,
Botucatu, São Paulo, Brasil 2010.
BARCELLOS,
L.
$\mathrm{J}$.
G.; NICOLAIEWSKY, S.; SOUZA, S. M. G.; LULHIER F. Plasmatic levels of cortisol in the response to acute stress in Nile tilapia, Oreochromis niloticus (L.), previously exposed to chronic stress. Aquaculture Research. v.30, p.437444, 1999.

BARROS M. M.; PEZZATO L. E.; KLEEMANN G. K.; HISANO H.; ROSA G. J. M. Níveis de vitamina $C$ e ferro para tilápia do Nilo (Oreochromis niloticus). Revista Brasileira de Zootecnia. 31:2149-2156, 2002.

BICUDO, A. J. A.; SADO, R. Y.; CYRINO, J. E. P. Growth, body composition and hematology of juvenile pacu (Piaractus mesopotamicus) fed increasing levels of ractopamine. Arquivo Brasileiro de Medicina Veterinária e Zootecnia, v. 64, n. 5, p. 1335-1342, 2012.

BOSCOLO, W. R.; HAYASHI, C. M.; SOARES, W. M.; FURUYA E F.; MEURER, C. Desempenho e Características de Carcaça de Machos 
Revertidos de Tilápias do Nilo (Oreochromis niloticus), Linhagens Tailandesa e Comum, nas Fases Inicial e de Crescimento. Revista Brasileira de Zootecnia v. 30, p. 1391-1396, 2009.

BRANDÃO, F. R.; DE CARVALHO GOMES, L.; CHAGAS, E. C. Respostas de estresse em pirarucu (Arapaima gigas) durante práticas de rotina em piscicultura. Acta Amazonica, v. 36, n. 3, p. 349, 2006.

FURUYA, W. M.; PEZZATO, L. E.; BARROS, M. M. Use of ideal protein concept for precision formulation of amino acids level in diets with and without di calcium phosphate for juvenile Nile tilapia. Aquaculture Research. v. 35, p. 110-116, 2010.

GOLDENFARB, P. B.; BOWYER, F. P.; HALL, E.; BROSIOUS, E. Reproducibility in the hematology laboratory: the microhematocrit determination. American Journal of Clinical Pathology, New York, v. 56, p. 35-39, 1971.

MARCHANT-FORDE, J. N.; LAY, D. C. JR.; PAJOR, E. A. The effects of ractopamine on the behavior and physiology of finishing pigs. Journal of Animal Science, v.81, p. 416-422, 2003.

MCDONALD, G.; MILLIGAN, L. Ionic, osmotic and acid-base regulation in stress. In: IWANA, G.K. et al. (Ed.). Fish stress and health in aquaculture. New York: Cambridge University Press, 1997. cap. 5, p. 119-144.

MCGRAW, D. W.; LIGGETT, S. B. Molecular mechanisms of beta2adrenergic receptor function and regulation. Proceedings of the American Thoracic Society, Stanford, v. 2, n. 4, p. 292-296, 2005.

MILLS, S. E.; SPURLOCK, M. E.; SMITH, D. J. Beta-adrenergic receptor subtypes that mediate ractopamine stimulation of lipolysis. Journal of Animal Science, Champaign, v. 81, n. 3, p. 662-668, 2003.

MPA. Ministério da Pesca e Aquicultura., 2010. Boletim estatístico da pesca e aquicultura 2010- Brasil. Disponible en: <http://www.mpa.gov.br> Acesso: 02 Out. 2014.

PEZZATO, L. E.; BARROS, M. M.; FRACALOSSI, D. M. et al. Nutrição de peixes. In: CYRINO, J. E. P.; URBINATI, E. C.; FRACALOSSI, D. M. (Ed.). Tópicos especiais em piscicultura de água doce tropical intensiva, São Paulo: Aquabil, p.75-172. 2004.

SANCHES, F. H. C. Resposta de estresse à substância de alarme na tilápia-do-nilo. 2013. 28f. Dissertação (Mestrado em Ciências Biológicas Zoologia) - Instituto de Biociências de Botucatu, Universidade Estadual Paulista. 2013.

SILVA, R. D.; ROCHA L. O.; FONTES D. A.; VIERA D.; FIORAVANTI M. C. Parâmetros hematológicos e bioquímicos da tilápia-do-Nilo (Oreochromis niloticus L.) sob estresse por exposição ao ar. Pesquisa Veterinária brasileira, v. 32 , n. supl. 1 , p. 99-107, 2012.

TAVARES-DIAS, M.; MORAES, F.R.; MARTINS, M.L.; KRONKA, S.N. Fauna parasitária de peixes oriundos de pesque-pagues do município de Franca, São Paulo, Brasil. II. Metazoários. Revista Brasileira de Zoologia, 18: 8195. 1999

TAVARES-DIAS, M.; MORAES, F. R. Características hematológicas da Tilapia rendalli capturada em "pesque-pague" de Franca, São Paulo, Brasil. Bioscience Journal, Uberlândia, v.19, p. 103-110, 2001.

UEDA, I. K.; EGAMI, M. I.; SASSO, W. S.; MATUSHIMA, E. R. 1997. Estudo hematológico do sangue periférico de $O$. nilocitus (Linneus, 
96

Indicators hematological and biochemical stress in tilapia (oreochromis niloticus) supplemented with ractopamine

1758). Brazilian Journal of

Veterinary Research and Animal

Science , 34:270-275.

WENDELAAR BONGA, S.E. The stress

response in fish. Physiol. Rev., v.77,

p.591-625, 1997.

Archives of Veterinary Science, v.21, n.2, p.87-96, 2016. 